\title{
Contribuições e dificuldades da abordagem de questões sociocientíficas na prática de professores de ciências*
}

\author{
Leonardo Fabio Martínez Pérez \\ Universidad Pedagogica Nacional \\ Washington Luiz Pacheco de Carvalho \\ Universidade Estadual Paulista "Júlio de Mesquita Filho"
}

Correspondência:

Leonardo Fabio Martínez Pérez

lemartinez@pedagogica.edu.co

* Agradecimento ao Programa de Estudantes - Convênio de PósGraduação (PEC-PG/CAPES/CNPq), pelo apoio financeiro para a realização desta pesquisa.

\section{Resumo}

Neste artigo, apresentamos os resultados de uma pesquisa sobre as contribuições e as dificuldades da abordagem de questões sociocientíficas na prática de professores de ciências em serviço. Na pesquisa realizada, de caráter qualitativo com corte crítico, a realidade é entendida como uma construção social subjetiva e intersubjetiva, marcada por um contexto histórico. A constituição dos dados foi feita no decorrer de uma disciplina sobre ensino de ciências a partir de questões sociocientíficas, desenvolvida em um curso de mestrado em ensino de química, e teve a participação de 31 professores de ciências em serviço. No intuito de garantir a validade de fidedignidade da pesquisa, foi utilizada mais de uma fonte de dados. Assim, os dados foram constituídos por meio de vários instrumentos, tais como: questionário inicial de caracterização dos participantes da pesquisa, gravações de entrevistas focais e trabalhos apresentados pelos professores sobre a abordagem de questões sociocientíficas (QSCs) em sala de aula. As análises alcançadas indicam que a abordagem de questões sociocientíficas possui um potencial considerável para a prática do professor em termos da tomada de decisão e do desenvolvimento de pensamento crítico dos alunos. 0 trabalho com questões sociocientíficas também exige planejamento do ensino e ações bem sustentadas, assim como a participação ativa do professor. Finalmente, são caracterizadas as dificuldades do trabalho realizado em termos pedagógicos, formativos e curriculares.

\section{Palavras-chave}

Formação de professores de ciências - Pesquisa qualitativa crítica Pensamento crítico - Tomada de decisão. 


\title{
Contributions and difficulties in dealing with social/ scientific issues in the practice of science teachers*
}

\author{
Leonardo Fabio Martínez Pérez \\ Universidad Pedagogica Nacional \\ Washington Luiz Pacheco de Carvalho \\ Universidade Estadual Paulista "Júlio de Mesquita Filho"
}

Contact:

Leonardo Fabio Martínez Pérez

lemartinez@pedagogica.edu.co

* Thanks to Students ProgramPostgraduation Agreement (PEC$P G / C A P E S / C N P q)$ for funding this research.

\begin{abstract}
This paper presents the results of a research about the contributions and difficulties in dealing with social/scientific issues related to the teaching practices of in-service science teachers. In this qualitative and critical research, reality is understood as a social construction that is both subjective and inter-subjective defined by a historical context. Data collection was conducted while a subject on science teaching was being delivered based on social/scientific issues, which took place in M.Sc. course on chemistry teaching and involved 31 in-service science teachers. With the purpose of assuring the research would be valid and trustworthy, more than one source of data was utilized. Thus data was gathered by recurring to several tools including: initial questionnaire to depict research participants, recording of focal interviews and assignments handed in by the teachers on social/scientific issues (SCIs) in the classroom. Analyses found that dealing with social/scientific issues has a considerable potential for the teaching practice in terms of decisionmaking and developing critical thinking by students. Teaching with the use of social/scientific issues also requires planning and wellsustained actions as well as the active participation of the teacher. Finally, difficulties are described in regard of the work done in its pedagogical, training and curricular aspects.
\end{abstract}

\section{Keywords}

Science teacher education - Critical qualitative research - Critical hinking - Decision-making. 
Pensar o ensino de ciências, desde a práxis do professor, requer necessariamente sua participação não só na definição das estratégias de ensino, mas também na defınição de problemas, conteúdos e objetivos associados à sua profissão. A ideia do professor como sujeito ativo de sua práxis é uma construção que precisa do estabelecimento de relações com seus pares (colegas, pesquisadores, administradores educativos etc.) em espaços sociais e históricos determinados.

No entanto, os professores de ciências enfrentam grandes dificuldades quando decidem trabalhar com seus alunos questões relativas a poder, raciocínio ético e ação responsável, uma vez que, tradicionalmente, a ciência e a tecnologia são abordadas em sala de aula como um conjunto de conhecimentos a serem assimilados sem maiores questionamentos, de forma que pouco é feito para que os estudantes interpretem a ciência como uma construção social, cultural e histórica (PEDRETTI, 2003; PEDRETTI et al., 2008).

Geralmente, os professores de ciências são especializados em disciplinas específıcas e não foram preparados para trabalhar aspectos sociais, políticos e éticos envolvidos em assuntos públicos adjacentes ao progresso científico e tecnológico. Nesse contexto, autores como Ramsey (1993), Watts et al. (1997) e Pedretti (1997, 2003) propõem a abordagem de questões sociocientíficas (QSCs) como uma forma de tratar, na prática dos professores, temas como natureza da ciência e da tecnologia, raciocínio ético-moral, reconstrução sociocrítica, ação responsável e sustentabilidade.

Levando em consideração as eventuais possibilidades da abordagem de QSCs no ensino de ciências, nosso objetivo de pesquisa consistiu em estudar as contribuições e as dificuldades dessa abordagem na prática do professor, por meio de análise crítica do desenvolvimento de uma disciplina sobre QSCs oferecida em um curso de mestrado em ensino de química.

As QSCs abrangem controvérsias sobre assuntos sociais que estão relacionados com conhecimentos científicos da atuali- dade e que, portanto, em termos gerais, são abordados nos meios de comunicação de massa (rádio, TV, jornal e internet). Questões como a clonagem, a manipulação de células-tronco, os transgênicos, o uso de biocombustíveis, a fertilização in vitro, os efeitos adversos da utilização da telecomunicação, a manipulação do genoma de seres vivos, o uso de produtos químicos, entre outras, envolvem consideráveis implicações científicas, tecnológicas, políticas e ambientais que podem ser trabalhadas em aulas de ciências com o intuito de favorecer a participação ativa dos estudantes em discussões escolares que enriqueçam seu crescimento pessoal e social.

\section{Metodologia}

Com o objetivo de caracterizar as contribuições e dificuldades da abordagem de QSCs na prática dos professores de ciências, estruturamos uma metodologia qualitativa. A principal razão para a escolha da perspectiva qualitativa corresponde ao nosso compromisso epistemológico com uma concepção crítica da pesquisa educacional, partindo do pressuposto de que a realidade não pode ser entendida como uma construção independente do sujeito cognoscitivo, pois ela é uma construção social subjetiva e intersubjetiva, marcada por um contexto histórico e influenciada por valores políticos, culturais e econômicos.

A pesquisa qualitativa de corte crítico é caracterizada pela análise e problematização da racionalidade técnica que reduz a atividade docente à mera aplicação de teorias, modelos ou estratégias criadas por agentes externos aos processos educativos. Esse tipo de pesquisa foi introduzido, principalmente, pelos trabalhos de Carr e Kemmis (1988), de Bodner e MacIsaac (1995), de Carr (1996) e de Kincheloe e McLaren (2006). Em coerência com uma teoria social crítica, esses autores questionaram a instrumentalização do conhecimento científico propagada pelo positivismo e reivindicaram a importância de 
se pensar os conhecimentos em relação a valores, interesses e ideologias. A pesquisa educacional crítica tem o compromisso ético de reconhecer as múltiplas vozes dos participantes, na medida em que estes interagem em um processo dialógico e criativo por meio do qual se constituem os dados e as análises.

Para o desenvolvimento do trabalho de campo da pesquisa, propusemos a realização de uma disciplina sobre QSCs em um curso de mestrado em ensino de química. No total, a disciplina teve três encontros presenciais de 4 horas e quatro encontros presenciais de 8 horas, somando 44 horas de trabalho presencial gravadas na íntegra em áudio para efeito das análises. Além desses encontros, foi organizado um grupo virtual no qual os professores tinham a possibilidade de interagir permanentemente. Esse espaço permaneceu aberto após o término do último encontro, servindo para postagem dos trabalhos finais dos professores e para eventuais discussões.

A fim de garantir a validade de fidedignidade da pesquisa realizada (MOLTO, 2002), foi utilizada mais de uma fonte de dados. Assim, os dados foram coletados por meio de vários instrumentos, tais como: questionário inicial de caracterização dos participantes da pesquisa, gravações de áudio de sete encontros realizados com os professores, entrevistas focais finais e trabalhos apresentados pelos professores sobre a abordagem de QSCs em sala de aula.

$\mathrm{Na}$ pesquisa, participaram 31 professores de ciências em serviço, a maioria deles com formação em licenciatura em química ou em licenciatura em química e biologia. A maior parte (45\%) dos professores possui um número considerável de anos de serviço docente (de seis a quinze anos); 34\% dos professores apresentam poucos anos de serviço (entre dois e cinco anos); e uma minoria (21\%) registra ampla experiência em anos de serviço docente (entre dezesseis e trinta anos).

Analisaremos diferentes episódios que representam os dados constituídos durante a pesquisa, os quais serão identificados por meio dos seguintes códigos: TF - trabalho final escrito pelos professores participantes da pesquisa; EF - entrevista focal desenvolvida com seis grupos de professores, a qual foi realizada ao final dos encontros da disciplina.

A transcrição dos episódios escolhidos e sua análise correspondente foram realizadas em conformidade com os seguintes sinais adaptados de Carvalho (2006) e Santos (2002): [...] trecho da transcrição omitido por não ser de interesse para análise; [xxx] - fala ininteligível; [ ] - inserção de comentários do pesquisador; ... - as reticências denotam prolongamento da ideia; PU - refere-se ao professor universitário e autor principal desta pesquisa; PP - professores participantes da pesquisa.

A partir da análise das informações coletadas pelos instrumentos expostos e da compreensão teórica da abordagem de QSCs em termos da perspectiva crítica do ensino de ciências, este artigo discute as dimensões de análise apresentadas a seguir: i) abordagem de QSCs e tomada de decisão; ii) abordagem de QSCs e pensamento crítico.

A tomada de decisão no ensino de ciências abrange o desenvolvimento de habilidades dos estudantes para realizarem suas próprias escolhas e a consideração da cultura dos estudantes, que influencia a forma como eles tomam suas próprias decisões. A discussão sobre QSCs em sala de aula parece oferecer melhores possibilidades para que os estudantes desenvolvam habilidades de pensamento crítico e melhorem a tomada de decisão.

Segundo Ratcliffe e Grace (2003), as QSCs abrangem a formação de opiniões e a escolha de juízos pessoais e sociais, implicam valores e aspectos éticos, e relacionam-se com problemas sociais de ordem local, nacional e global.

As controvérsias envolvidas nas discussões públicas sobre QSCs exigem a formação de cidadãos dotados de conhecimentos e capacidades para avaliar responsavelmente problemas científicos e tecnológicos na sociedade atual e abrangem aspectos multidisciplinares (ABD-EL-KHALICK, 2003). 


\section{Abordagem de questões sociocientíficas e tomada de decisão}

As discussões desenvolvidas com os professores sobre a importância da pesquisa como parte de sua atuação docente e de sua formação no curso de mestrado possibilitaram que eles fossem assumindo a abordagem de QSCs de seu interesse como um projeto de pesquisa de seu ensino.

A título de exemplo, apresentamos, nos Quadros 1 e 2, uma síntese dos objetivos, referenciais teóricos, procedimentos metodológicos e conclusões de alguns trabalhos que foram entregues pelos $\mathrm{PP}^{1}$ após a finalização da disciplina de ensino de ciências a partir de QSCs. Levando em consideração os dados obtidos a partir dos trabalhos dos professores e de episódios registrados nas gravações de áudio das entrevistas, caracterizamos a forma como os professores avançaram na pesquisa sobre sua prática a partir da abordagem de QSCs.

De acordo com os dados registrados no Quadro 1, evidenciamos que os professores Pedro e Vinicius ${ }^{2}$ não consideraram, em seus trabalhos, um objetivo de ensino específico sobre a abordagem de QSCs. No caso do professor Pedro, seu trabalho esteve limitado à descrição de dados sobre a automedicação, os quais foram levantados com seus estudantes, que participavam de um curso técnico de farmácia oferecido a distância. As conclusões apresentadas pelo professor são limitadas à descrição das causas da automedicação apontadas por moradores de uma cidade da Colômbia.

Quadro 1 - Síntese de trabalhos apresentados pelos professores Pedro e Vinicius

\begin{tabular}{|c|c|c|}
\hline & \multicolumn{2}{|l|}{ Nomes dos professores } \\
\hline & Pedro & Vinicius \\
\hline $\begin{array}{l}\text { Objetivos propostos } \\
\text { pelos professores }\end{array}$ & $\begin{array}{l}\text { - Determinar as causas que influem na automedicação e seus efeitos } \\
\text { secundários na saúde e na sociedade dos habitantes de uma cidade da } \\
\text { Colômbia. }\end{array}$ & $\begin{array}{l}\text { - Diminuir os fatores de risco rela- } \\
\text { cionados com o consumo de tabaco. }\end{array}$ \\
\hline Referenciais teóricos & $\begin{array}{l}\text { - Teorias sobre a saúde. } \\
\text { - Aspectos legais sobre a saúde pública. }\end{array}$ & $\begin{array}{l}\text { - Tabagismo. } \\
\text { - Problemas de saúde. }\end{array}$ \\
\hline $\begin{array}{l}\text { Procedimentos } \\
\text { metodológicos }\end{array}$ & $\begin{array}{l}\text { - Metodologia quantitativa descritiva com o uso de questionários e obser- } \\
\text { vações. }\end{array}$ & $\begin{array}{l}\text { - Sensibilização sobre o tema e ca- } \\
\text { racterização de ideias prévias. } \\
\text { - Realização de oficinas }\end{array}$ \\
\hline Conclusões & $\begin{array}{l}\text { - } 0 \text { uso de medicamentos sem formula médica é uma prática generalizada } \\
\text { em famílias da cidade da Colômbia estudada. As pessoas têm o costume de } \\
\text { procurar medicamentos nas farmácias e, se a doença continua, procuram } \\
\text { ajuda médica. } \\
\text { - Alguns fatores que geram a automedicação são: a) burocracia no } \\
\text { atendimento do sistema de saúde público; b) dificuldade no sistema } \\
\text { de transporte; c) falta de tempo para assistir a consultas médicas; d) } \\
\text { desinformação da população. }\end{array}$ & $\begin{array}{l}\text { - } 0 \text { tabagismo é um grave problema } \\
\text { que exige } 0 \text { compromisso dos } \\
\text { diferentes atores sociais, o que } \\
\text { requer a elaboração de políticas mais } \\
\text { amplas que gerem ações concretas } \\
\text { para abordar o problema. }\end{array}$ \\
\hline
\end{tabular}

Fonte: MARTÍNEZ, 2010

Apesar de o professor Pedro participar de todos os encontros da disciplina e realizar comentários sobre as propostas de seus colegas, ele não conseguiu abordar pedagogicamente uma QSC em sua prática. Uma

1- Os PP realizavam o segundo ano do curso de mestrado e, portanto, todos eles tinham estudado disciplinas relacionadas com pesquisa. possível explicação para essa situação pode ser atribuída à preparação e à experiência docente desse professor, pois, como bacharel em química farmacêutica, a maior parte de sua experiência profissional não esteve vinculada

2-Todos os nomes dos professores apresentados nas análises são fictícios. 
à docência, uma vez que, dos dezesseis anos passados após a conclusão do bacharelado, somente sete foram vinculados à docência universitária, e não foi registrada experiência alguma no ensino básico.

0 caso do professor Vinicius é diferente, pois ele possuía uma ampla experiência docente no ensino superior e no ensino básico, num total de trinta anos de serviço. 0 professor realizou seu trabalho final sobre um programa de tabagismo para ensino fundamental, focado em estratégias de prevenção.

Conforme o Quadro 2, observamos que a professora Roberta salienta, nas conclusões de seu trabalho, o conflito existente entre a cultura dos estudantes (adolescentes) e a cultura do professor de ciências. A primeira é caracterizada pela espontaneidade e pelas experiências cotidianas dos estudantes que não têm interesse de abordar o processo de tomada de decisão de forma sistemática e fundamentada. A cultura do professor de ciências caracteriza-se pela preocupação acadêmica em fundamentar a tomada de decisão como um processo sistemático.

Nos referenciais teóricos utilizados pelas professoras Roberta e Cristina (Quadro 2), evidenciamos a apropriação de várias pesquisas sobre a tomada de decisão no ensino de ciências.

Os estudos de Santos e Mortimer (2001) e de Ratcliffe (1997) apresentam diferentes modelos para orientar a tomada de decisão, os quais foram utilizados pelas professoras Roberta e Cristina para desenvolver suas atividades em sala de aula e, dessa forma, garantir o caráter acadêmico de seu trabalho.

É interessante destacar que o conflito entre a cultura dos estudantes e a cultura acadêmica do professor de ciências é enfrentado pela professora Roberta por meio do diálogo de saberes que foi desenvolvido no decorrer do jogo de papéis e no trabalho colaborativo realizado com seus estudantes.

A partir do Episódio 1, identificamos o conflito citado anteriormente e a forma como a professora Roberta enfrenta-o.

\section{Episódio 13 (EF Grupo 2)}

1. PU: [...] Então, vamos conversar um pouquinho. 0 trabalho desenvolvido durante a disciplina lhes permitiu repensar sua prática docente? Permitiu-lhes ou não lhes permitiu? E como lhes permitiu repensar sua prática docente?

5. Roberta: [...] uma coisa que tem sido muito difícil de vencer na turma é a atitude e seus próprios interesses [dos estudantes], que são colocados por cima do interesse acadêmico. Isso tem sido um processo de tensões, eu cedo um pouco para avançar. Tem sido um processo de negociação, não explícita, mas implícita. No entanto, eu tenho gostado do que temos feito...

0 conflito entre cultura juvenil e cultura acadêmica é um tema pouco explorado no ensino de ciências e na formação de professores da área. No entanto, alguns trabalhos, tais como os desenvolvidos por Leal e Rocha (2008), Corti, Freitas e Spósito (2001) e Corti e Souza (2005), oferecem importantes elementos para pensar o conflito em termos de processos de negociação e diálogo.

Santomé (2001) discute a forma como a cultura juvenil constitui uma das culturas silenciadas ou negadas no currículo, na medida em que sua construção idiossincrática é ignorada frequentemente nos processos de ensino. Nesse sentido, a negociação e o diálogo de saberes proposto pela professora Roberta na abordagem de sua QSC constitui uma possibilidade importante para aproximar culturas diferentes em sala de aula que configuram conflitos no espaço escolar, sobretudo quando a possibilidade do diálogo persuasivo ou polifônico é desconsiderada.

0 ensino de ciências voltado à tomada de decisão por parte dos estudantes é reconstituído como um processo de negociação. Portanto, não se trata simplesmente de ensinar as estratégias metodológicas para que os estudantes possam

3 - Todos os episódios que serão apresentados foram traduzidos pelos autores da pesquisa. 
Quadro 2 - Síntese de alguns trabalhos apresentados pelos professores em serviço

\begin{tabular}{|c|c|c|c|c|}
\hline $\begin{array}{c}\text { Nome do professor } \\
\text { e QSC trabalhada }\end{array}$ & $\begin{array}{l}\text { Objetivos propostos } \\
\text { pelos professores }\end{array}$ & $\begin{array}{l}\text { Referenciais } \\
\text { teóricos }\end{array}$ & Procedimentos metodológicos & Conclusões \\
\hline $\begin{array}{l}\text { Roberta: } \\
\text { A segurança ali- } \\
\text { mentar e seus efei- } \\
\text { tos sociais. }\end{array}$ & $\begin{array}{l}\text { - Formar os estu- } \\
\text { dantes para a parti- } \\
\text { cipação cidadã por } \\
\text { meio da reflexão } \\
\text { de seu saber sobre } \\
\text { uma QSC para fa- } \\
\text { vorecer a tomada de } \\
\text { decisão. }\end{array}$ & $\begin{array}{l}\text { - Diálogo de } \\
\text { saberes. } \\
\text { - Tomada de } \\
\text { decisão. }\end{array}$ & $\begin{array}{l}\text { Metodologia qualitativa focada no di- } \\
\text { álogo de saberes e estruturada nas } \\
\text { 1) caracterização da questão sobre a } \\
\text { segurança alimentar no contexto da } \\
\text { crise ambiental; 2) estudo e discussão } \\
\text { da questão; 3) identificação de atores } \\
\text { sociais relacionados com a QSC e jogo } \\
\text { de papéis; 4) análise do processo de } \\
\text { tomada de decisão. }\end{array}$ & $\begin{array}{l}\text { - } 0 \text { conflito entre cultura dos estudantes e } \\
\text { cultura do professor influi no processo de } \\
\text { tomada de decisão. } \\
\text { - A cultura juvenil pode fomentar a partici- } \\
\text { pação dos estudantes e gerar processos } \\
\text { de conscientização neles. } \\
\text { - A perspectiva CTSA melhora o planeja- } \\
\text { mento e o desenvolvimento do microcur- } \\
\text { rículo (ensino da professora) e gera novas } \\
\text { dinâmicas em sala de aula. }\end{array}$ \\
\hline $\begin{array}{ll}\text { Cristina: } & \\
\text { Conservação } & \text { do } \\
\text { recurso hídrico no } & \text { nontexto escolar. }\end{array}$ & $\begin{array}{l}\text { Desenvolver nos es- } \\
\text { tudantes a tomada } \\
\text { de decisão como } \\
\text { uma potencialidade } \\
\text { humana a partir da } \\
\text { QSC relacionada } \\
\text { com a importância } \\
\text { e a preservação do } \\
\text { recurso hídrico. }\end{array}$ & $\begin{array}{l}\text { - QSC e pers- } \\
\text { pectiva CTSA. } \\
\text {-Tomada de } \\
\text { decisão. }\end{array}$ & $\begin{array}{l}\text { Metodologia descritiva organizada nas } \\
\text { seguintes etapas: } \\
\text { 1) leitura de notícias de jornal } \\
\text { relacionadas à problemática da água; 2) } \\
\text { espaços de reflexão e discussão sobre } \\
\text { a QSC. }\end{array}$ & $\begin{array}{l}\text { - Muitos estudantes desconhecem a } \\
\text { QSC sobre a conservação da água, na } \\
\text { medida em que não são capazes de } \\
\text { valorizar a questão nem de estabelecer } \\
\text { as implicações CTS. Apesar de a questão } \\
\text { ser atual e da considerável quantidade } \\
\text { de informação sobre ela na mídia, foi } \\
\text { necessário trabalhar com os estudantes } \\
\text { discussões com o objetivo de analisar as } \\
\text { implicações socioambientais da questão. }\end{array}$ \\
\hline $\begin{array}{l}\text { Mauricio: } \\
\text { Consumo de drogas } \\
\text { por adolescentes. }\end{array}$ & $\begin{array}{l}\text { Potencializar nos } \\
\text { estudantes a toma- } \\
\text { da de decisão com } \\
\text { respeito ao consumo } \\
\text { de drogas. }\end{array}$ & $\begin{array}{l}\text {-Consumo } \\
\text { de drogas na } \\
\text { Colômbia. } \\
\text { - Drogas uti- } \\
\text { lizadas pelos } \\
\text { adolescentes. } \\
\text {-Consequên- } \\
\text { cias do consu- } \\
\text { mo de drogas }\end{array}$ & $\begin{array}{l}\text { Metodologia quantitativa estrutura nas } \\
\text { seguintes etapas: } \\
\text { 1) trabalho inicial com estudantes } \\
\text { utilizando um vídeo sobre drogas e } \\
\text { estudo de um artigo sobre o tema; 2) } \\
\text { aplicação de um questionário. }\end{array}$ & $\begin{array}{l}\text { - É necessário mostrar aos jovens as } \\
\text { consequências do consumo de drogas } \\
\text { para que eles possam tomar decisões da } \\
\text { melhor forma. } \\
\text { - Os estudantes interessaram-se pela } \\
\text { QSC. } \\
\text { - Não somente é importante cumprir } \\
\text { [ensinar] os conteúdos estabelecidos no } \\
\text { currículo, mas também é importante tra- } \\
\text { balhar as problemáticas educativas. }\end{array}$ \\
\hline $\begin{array}{l}\text { Laura: } \\
0 \text { problema da pro- } \\
\text { dução e disposição } \\
\text { do lixo. }\end{array}$ & $\begin{array}{l}\text { - Explorar e carac- } \\
\text { terizar aspectos da } \\
\text { tomada de decisão } \\
\text { diante da questão so- } \\
\text { ciocientífica proposta. } \\
\text { - Desenvolver um pro- } \\
\text { cesso de tomada de } \\
\text { decisão diante da pro- } \\
\text { dução e da disposição } \\
\text { de lixo na escola. }\end{array}$ & $\begin{array}{l}\text { - Educação } \\
\text { CTSA. } \\
\text { - Tomada de } \\
\text { decisão. }\end{array}$ & $\begin{array}{l}\text { Metodologia descritiva de acordo com } \\
\text { as seguintes etapas: } \\
\text { 1) aplicação de um questionário ini- } \\
\text { cial; 2) explicação e discussão de as- } \\
\text { pectos relacionados com a produção e } \\
\text { a disposição de lixo; 3) trabalho sobre } \\
\text { a tomada de decisão; 4) aplicação de } \\
\text { questionário final. }\end{array}$ & $\begin{array}{l}\text { - A maioria de respostas oferecidas } \\
\text { pelos estudantes mostra que a toma- } \\
\text { da de uma decisão simples, tal como } \\
\text { a desenvolvida para colocar o lixo no } \\
\text { local adequado, implica dinâmicas edu- } \\
\text { cativas mais complexas e difíceis, não } \\
\text { sendo um simples processo mecânico. } \\
\text { - Como professores de ciências, temos } \\
\text { um papel e uma responsabilidade na } \\
\text { formação dos estudantes; em tal sen- } \\
\text { tido, devemos trabalhar as dimensões } \\
\text { conceitual e atitudinal, bem como va- } \\
\text { lores que favoreçam o compromisso e } \\
\text { a participação social nos processos de } \\
\text { tomada de decisão desenvolvidos pelos } \\
\text { estudantes. }\end{array}$ \\
\hline $\begin{array}{l}\text { Fátima: } \\
\text { Implicações sociais } \\
\text { dos xenobióticos na } \\
\text { saúde. }\end{array}$ & $\begin{array}{l}\text { - Analisar a abor- } \\
\text { dagem de questões } \\
\text { sociocientíficas } \\
\text { para orientar o en- } \\
\text { sino de bioquímica } \\
\text { para estudantes de } \\
\text { fisioterapia. }\end{array}$ & $\begin{array}{l}\text { - Perspectiva } \\
\text { CTSA e QSC. }\end{array}$ & $\begin{array}{l}\text { Metodologia qualitativa descritiva } \\
\text { organizada nas seguintes etapas: } \\
\text { 1) caracterização de habilidades de } \\
\text { pensamento crítico; 2) estudo de } \\
\text { aspectos socioambientais. }\end{array}$ & $\begin{array}{l}\text { - Os conteúdos de bioquímica têm } \\
\text { sentido para os estudantes defisioterapia } \\
\text { quando eles os relacionam com } \\
\text { problemas de seu futuro profissional e } \\
\text { contribuem para desenvolver habilidades } \\
\text { de pensamento. } \\
\text { - Os estudantes interessam-se pela } \\
\text { aprendizagem da bioquímica quando } \\
\text { abordam questões socioambientais. }\end{array}$ \\
\hline
\end{tabular}

Fonte: MARTíNEZ, 2010. 
tomar decisões responsáveis, como geralmente se propõe nas pesquisas da área de ensino de ciências (RATCLIFFE, 1997; KORTLAND, 1996). 0 problema também estaria relacionado com aspectos interculturais estabelecidos em sala de aula.

A professora Roberta, em vez de desconsiderar o conflito cultural expresso nas discussões realizadas com seus estudantes, valoriza-o e busca avançar nos processos de ensino voltados à tomada de decisão conforme as expressões culturais dos alunos.

A seguir, apresentamos um recorte do trabalho final entregue pela professora Roberta, o qual evidencia o diálogo de saberes como um processo importante para favorecer aspectos relacionados com a tomada de decisão, tais como identificação do problema e avaliação dos custos e benefícios.

\section{Recorte do TF da professora Roberta}

[...] Tem-se reconhecido, neste trabalho, que a complexidade do trabalho realizado em sala de aula deriva de alguns elementos antagônicos [contraditórios] próprios dos ambientes humanos. No entanto, é necessário reconhecer que a cultura juvenil é um fator determinante no desenvolvimento de estratégias didáticas. 0 docente não deve esquecer a dinâmica escolar, e também não pode esquecer os mundos que entram em contato [em sala de aula]. Por um lado, o mundo acadêmico do professor, que apesar de reconhecer a individualidade, não se afasta da realidade do que para ele ou para ela constitui uma perturbação: "chamar a atenção dos estudantes”, convidando-os para o diálogo de saberes, o qual não é um ato fácil [...]. Os elementos da cultura juvenil "da forma de ser jovem" e as complexidades em sala de aula, em um caso de tomada de decisão diante da questão sobre que tipo de agricultura urbana desenvolver na escola: orgânica, transgênica, hidroponia, agroquímica? [...]. Por exemplo, diante da pergunta "que elementos são importantes para decidir corretamente em um grupo social o tipo de prática agrícola de plantio?" As opções apresentadas na discussão pelos estudantes foram: conhecimento, custo, pobreza, tecnologia agrícola e manipulação genética de sementes:

Estudante 4: Pois, pela ignorância, não avançamos no conhecimento, você me entende! As pessoas deveriam produzir melhores produtos, você entende como é a vida, não é? Há que plantar sem químicos, isto tem que ser "algo leve", você me entende. Professora: Alguém pode me explicar o que é algo "leve" neste caso?

Estudante 5: 0 que ele quer dizer [estudante 4] é que, produzindo melhores frutos, as pessoas vão comercializar melhor e vão receber melhores ingressos para poder melhorar a tecnologia e a vida.

Professora: Ou seja, que você acredita que a qualidade dos produtos influencia na qualidade de vida e isto faz com que pensemos em melhores tecnologias para o plantio.

Estudiante 6: Isso professora! "Um abraço para os caras do rap" [o estudante provavelmente fala dessa forma porque a aula estava sendo filmada pela professora e os outros estudantes dão risada].

Podemos observar na fala exposta anteriormente que os estudantes incluem em suas respostas elementos de sua cultura juvenil, compreendem o contexto [social, no qual vivem] e fazem uso de expressões juvenis no processo de tomada de decisão. É relevante considerar que o contexto sociocientífico pode ser analisado para a tomada de decisões, para o exercício da cidadania diante da questão de segurança alimentar. Essa compreensão é característica dos elementos próprios da cultura juvenil [mas da cultura acadêmica do professor].

Em contraste com o diálogo de saberes proposto pela professora Roberta, a professora 
Cristina, nas conclusões de seu trabalho final (Quadro 2), expressa que, apesar da importância da QSC abordada em sala de aula sobre as consequências sociais e ambientais relacionadas com o desperdício de água, os jovens não evidenciam um avanço significativo para uma tomada de decisão responsável.

Percebemos, no trabalho da professora Cristina, um grande esforço para preparar os estudantes para a tomada de decisão segundo esquemas metodológicos conforme a cultura acadêmica que ela representa em sala de aula como professora de ciências. No entanto, a pouca atenção prestada à cultura juvenil de seus estudantes poderia ser um fator limitante dos resultados obtidos por ela.

A partir das análises realizadas sobre os trabalhos das professoras Roberta e Cristina, podemos inferir que a cultura dos estudantes (cultura juvenil) influi na tarefa de alcançar os objetivos de ensino propostos na abordagem de uma QSC em sala de aula. Parece não ser suficiente que as QSCs sejam impactantes em termos socioambientais. Para interessar aos alunos e engajá-los na tomada de decisão, é necessário aproveitar a riqueza existente no diálogo entre a cultura juvenil e a cultura acadêmica dos professores.

Os currículos escolares e, portanto, os professores que desconsideram a cultura de seus estudantes podem estar perdendo a oportunidade de estabelecer diálogos significativos. 0 encontro entre diferentes saberes oferece possibilidades enriquecedoras para que os estudantes percebam e reconheçam que sua visão de jovem pode ser ampliada com outras visões expressas por seus professores e colegas. Santomé (2001) salienta a importância de se levar em consideração o encontro cultural na escola, na medida em que as disciplinas acadêmicas do currículo devem vincular os contextos e as realidades de jovens e crianças, de tal forma que eles possam compreender suas realidades e comprometer-se em sua transformação. É interessante a observação apresentada pela professora Laura de que a tomada de decisão não é um processo simples de agir de forma bem comportada, referindo-se à disposição dos estudantes para colocar os resíduos descartáveis (lixo) no local certo (Quadro 2). A tomada de decisão estaria relacionada tanto à mudança atitudinal dos estudantes, quanto à construção de determinados valores que lhes possibilitem um comportamento e um agir mais consistentes.

A conclusão estabelecida pela professora Laura mostra que uma decisão simples, tal como colocar os resíduos no local certo, pode envolver um processo complexo, uma vez que o trabalho desenvolvido por ela era com crianças de ensino fundamental do quinto ano. A partir do Episódio 2, podemos identificar a dificuldade exposta pela professora e a forma como ela a enfrentou por meio de atividades específicas.

\section{Episódio 2 (EF Grupo 6)}

7. PU: Bom! Muito obrigado. Nesse processo que vocês têm desenvolvido, que tipo de tensões ou dificuldades têm enfrentado e como as têm enfrentado?

16. Laura: Na verdade, quando você falou que devíamos encontrar uma QSC, eu pensava nas crianças tão pequeninas e também pensava "até onde eu posso trabalhar uma QSC com elas?”; essa era a primeira questão que me fazia, e a segunda: "como oriento meu trabalho?". Sei que o primeiro que devo fazer é oferecer-lhes [aos estudantes] uma informação sobre o que é uma decisão para não limitar sua participação espontânea.

17. PU: como enfrentou essa dificuldade?

18. Laura: Pensando em como faria atividades específıcas para olhar a participação dos estudantes e avaliar o avanço dessa dificuldade.

0 caso do professor Mauricio é interessante, porque ele não tinha uma preocupação de pesquisa com o ensino de ciências, pois se havia formado como bacharel em química. Além disso, ele mesmo reconhecia que se limitava a ensinar os conteúdos específicos de 
química; no entanto, essa visão foi ampliada com o trabalho realizado em sala de aula com a QSC de seu interesse.

No Episódio 3, observamos que o professor Mauricio ainda considera a questão social como um aspecto estranho ao ensino de sua disciplina, mas ele começa a valorizar a inovação trazida pela abordagem de QSCs, sobretudo quando se enfrentam assuntos morais. 0 avanço do professor é ratificado nas conclusões estabelecidas por ele em seu trabalho final (Quadro 2), nas quais ele reconhece a importância das problemáticas educativas e sociais, bem como dos conteúdos disciplinares de ciências.

\section{Episódio 3 (EF Grupo 1)}

1. PU: [...] Primeiro, vamos conversar sobre o seguinte: o trabalho que temos desenvolvido durante a disciplina lhes tem ajudado a repensar sua prática de ensino? Ou seja, lhes tem ajudado em considerar como trabalham ou não lhes tem ajudado, por que não lhes têm ajudado?

7. Mauricio: Focava-me só na parte científica, mas há uma parte social importante. A parte do desenvolvimento de pensamento crítico e a tomada de decisões é importante. Também que considerem [os estudantes] a parte formal [da disciplina de química].

A abordagem de QSCs, voltada a favorecer processos de tomada de decisão nos estudantes do ensino básico, não deve considerar apenas as estratégias didáticas para estruturar e fundamentar as escolhas dos estudantes, pois é relevante também levar em conta aspectos culturais dos estudantes e da escola que influem na forma como eles posicionam-se e realizam suas escolhas. A análise das implicações educacionais do encontro cultural entre jovens e professores em sala de aula, constitui um campo de trabalho interessante para o ensino de ciências focado na preparação dos estudantes para participar ativamente na sociedade por meio de posicionamentos que valorizem seus inte- resses, mas também que destaquem a importância da reflexão racional envolvida nesses posicionamentos.

\section{Abordagem de questões sociocientíficas e pensamento crítico}

No caso da professora Fátima, a habilidade de pensamento crítico trabalhada com seus estudantes correspondeu à habilidade para solucionar problemas a partir do estudo de casos clínicos sobre xenobióticos, que era a QSC abordada em sua aula de bioquímica ministrada para estudantes de fisioterapia (Quadro 2).

A professora adotou a proposta de Kortland (1996) para abordar a solução de problemas com seus estudantes, e, em conformidade com tal autor, ela estabeleceu critérios para avaliação de alternativas que permitissem solucionar os problemas estipulados após monitorar as implicações da solução proposta.

Os resultados obtidos pela professora Fátima indicam que 55\% de seus estudantes avaliaram os efeitos dos xenobióticos nos casos clínicos estudados, levando em consideração as propriedades químicas dessas substâncias, seus mecanismos de ação e os resultados de testes de sangue e urina. Outra porcentagem de estudantes (25\%) avaliou os sintomas e as vias de intoxicação relacionadas aos xenobióticos; os 20\% restantes de estudantes basearam suas soluções na análise de histórias clínicas. A partir desses dados, a professora apresenta indícios do desenvolvimento de habilidades dos estudantes para solucionar problemas.

No Episódio 4, identificamos que a professora Fátima valoriza o trabalho realizado sobre as QSCs, pois este enriqueceu seus fazeres pedagógicos, favoreceu a motivação de seus estudantes, possibilitou o desenvolvimento de algumas habilidades de pensamento crítico e ajudou-a a melhorar e dinamizar os processos de ensino e aprendizagem das ciências. 


\section{Episódio 4 (EF Grupo 2)}

1. PU: [...] Então, vamos conversar um pouquinho. 0 trabalho desenvolvido durante a disciplina lhes permitiu repensar sua prática docente? Permitiu-lhes ou não lhes permitiu? E como lhes permitiu repensar sua prática docente? [...]

4. Fátima: Parece-me que tem servido para perceber que tão terrível estava, que vinha aplicando a mesma metodologia. 0 processo tem me ajudado para ver se eles [os estudantes] estão compreendendo os conceitos. Não estavam aprendendo. A abordagem da QSCs através de casos clínicos permitiu não somente ser mais próximo dos estudantes, mas também conhecê-los. [...] Permitiu-me evidenciar que agora encontram [os estudantes] sentido à bioquímica permitindo vincular os conceitos com a vida real, então isto serve. Essas enzimas, esses processos metabólicos servem para algo, pois trabalhando a questão dos antibióticos, percebem como são esses conceitos. A QSC permite abrir mais espaços de reflexão, evidenciar outros aspectos da dimensão moral...

Da mesma forma que a professora Fátima, o professor Antônio e as professoras Adriana e Fernanda concordaram, nas conclusões de seus trabalhos, que a abordagem de QSCs permitiu-lhes desenvolver algum tipo de habilidade de pensamento crítico em seus estudantes. 0 professor e as professoras expuseram, em seus trabalhos, referenciais teóricos sobre o desenvolvimento de pensamento crítico, conforme Halpern $(1998,2006)$. Segundo esse referencial, os professores entendem o pensamento crítico como um processo reflexivo e racional por meio do qual os indivíduos decidem o que fazer e no que acreditar diante de determinadas situações ou problemas.

Embasados no autor citado, os professores salientaram a habilidade de análise de argumentos, a habilidade de tomada de decisão e a habilidade de solução de problemas como habilidades de ordem superior, as quais evidenciam o desenvolvimento do pensamento crítico. Também salientaram outras habilidades básicas que caracterizam uma pessoa crítica: a) habilidade para formular questionamentos diante de determinado problema; b) habilidade para buscar informações pertinentes ao tema objeto de discussão; c) habilidade para analisar diferentes pontos de vista; d) habilidade para utilizar conceitos com o intuito de compreender implicações e consequências de determinada decisão ou ação.

A professora Fernanda, nas análises de seu trabalho, comenta o desenvolvimento de habilidades de argumentação de seus estudantes de acordo com a qualidade das opiniões emitidas por eles durante os debates realizados. Nesse sentido, ela expressa que aproximadamente $10 \%$ dos estudantes manifestaram opiniões tais como "Não concordo com a clonagem porque não concordo", sem apresentar justificativa alguma. No entanto, aproximadamente $30 \%$ de seus estudantes manifestaram opiniões com o seguinte tipo de justificativa:

\section{Não concordo com a experimentação com animais, porque esse tipo de experimentação não oferece resultados comparáveis, pois os animais, por mais parecidos que sejam aos seres humanos, não funcionam da mesma maneira.}

Por sua vez, 60\% dos estudantes tentaram incorporar em suas opiniões aspectos éticos:

Não concordo com a experimentação utilizando animais, porque essa experimentação vai contra a vida, pois todos os seres vivos têm direito a viver; aliás, como vamos saber que um remédio atua da mesma forma no olho de um coelho, que no olho de uma pessoa, sabendo que o olho do coelho é diferente do olho humano? Se fôssemos nós que fôssemos utilizados na experimentação, como nos sentiríamos? 
Embasada em tais resultados e análises, a professora Fernanda conclui que é possível desenvolver habilidades básicas de pensamento crítico ao trabalhar em sala de aula a QSC de seu interesse, segundo metodologias didáticas fundamentadas na perspectiva Ciência, Tecnologia, Sociedade e Ambiente (CTSA).

No caso do professor Antônio e da professora Adriana, a explicação de avanços a respeito das habilidades do pensamento crítico em seus estudantes é realizada em termos gerais, sem oferecer evidências específicas. Por exemplo, o professor Antônio menciona que os grupos dos estudantes conformados para trabalhar a QSC dos biocombustíveis e hidrocarbonetos desenvolviam habilidades básicas, como a interpretação de dados para fundamentar as discussões. Já no caso da professora Adriana, ela apenas propõe um esquema metodológico para o desenvolvimento de habilidades de pensamento crítico e oferece algumas reflexões sobre esse esquema, sem indicar os avanços construídos com os estudantes.

Algumas razões que podem explicar as limitações evidenciadas particularmente pelo professor Antônio estão relacionadas com a falta de preparação em pesquisa educacional e com a dinâmica escolar na qual ele realizava seu trabalho. No caso da professora Adriana, a dificuldade é apontada na articulação entre a QSC e o conteúdo específico de ciências, que ela aborda segundo um ensino tradicional. Nos Episódios 5 e 6, evidenciamos essas dificuldades e identificamos as contribuições da abordagem das QSCs no melhoramento das práticas docentes do professor Antônio e da professora Adriana.

\section{Episódio 5 (EF Grupo 4)}

6. PU: Bom! No trabalho que vocês desenvolveram sobre as questões sociocientíficas, que tipo de tensões ou dificuldades vocês enfrentaram?

18: Antônio: Questões internas [referendo-se a dinâmica escolar], como dizia a colega [Andrea]. Como aprender a en- sinar [conforme a abordagem de QSC]? Como se faz um trabalho de pesquisa? [...] porque a pesquisa é fundamental para a docência, de fato não é fácil aprender bem a metodologia de pesquisa. Nos aspectos externos, temos o tempo estabelecido pela escola.

\section{Episódio 6 (EF Grupo 1)}

1. PU: [...] Primeiro, vamos conversar sobre o seguinte: o trabalho que temos desenvolvido durante a disciplina lhes tem ajudado a repensar sua prática de ensino? Ou seja, lhes tem ajudado a considerar como trabalham ou não lhes têm ajudado, por que não lhes têm ajudado?

7. Adriana: A dificuldade não tem sido exclusivamente do currículo, porque o tempo tem sido investido no debate [sobre QSC]. Estavam tão emocionados [estudantes] que nós passamos [do tempo]. A outra parte é que devemos amenizar as temáticas que seriam os hidrocarbonetos, $\mathrm{e}$ como é isso.

No Episódio 7, identificamos que a professora Fernanda valoriza o trabalho realizado sobre QSCs porque este enriqueceu seus fazeres pedagógicos, favoreceu a motivação de seus estudantes, possibilitou o desenvolvimento de algumas habilidades de pensamento crítico e ajudou-a a melhorar e dinamizar os processos de ensino e aprendizagem de ciências.

\section{Episódio 7 (EF Grupo 2)}

1. PU: [...] Então, vamos conversar um pouquinho. 0 trabalho desenvolvido durante a disciplina lhes permitiu repensar sua prática docente? Permitiu-lhes ou não lhes permitiu? E como lhes permitiu repensar sua prática docente?

3. Fernanda: Para mim tem sido muito enriquecedor. Também como diz Edith, porque tenho percebido que, em meu fazer pedagógico, os estudantes têm maior motivação [...]. Parece-me importante que, em cada encontro que tenho com 
estudantes, eu penso e analiso o que estou fazendo em sala de aula, penso em que perguntas eu deveria fazer para gerar mais debate, melhorar sua argumentação, seu pensamento crítico. Em relação com meu trabalho de pesquisa, penso que o pensamento crítico e as QSCs podem ir juntos. Eu falava algumas vezes sobre a ciência, mas esquecia de formar cidadãos com uma fundamentação teórica. Como vou fazer, como posso melhorar...

Em termos gerais, podemos dizer, conforme os episódios analisados, que a abordagem de QSCs por parte da professora Fátima possibilitou desenvolver habilidades de pensamento crítico em seus estudantes, na medida em que ela foi desenvolvendo seu ensino como um processo de pesquisa.

\section{Considerações finais}

A abordagem de QSCs no ensino de ciências não pode ser reduzida aos conteúdos específicos de ciências, porque, apesar de serem relevantes para a educação científica e tecnológica dos cidadãos, não são sufıcientes para abordar as questões sociais, políticas e éticas atreladas ao progresso científico e tecnológico. Nesse sentido, é importante que o professor de ciências mobilize uma diversidade de conhecimentos e de fontes diversificadas sobre assuntos políticos, sociais, científicos e pedagógicos que lhe permitam favorecer o crescimento pessoal e social de seus estudantes.

0 ensino de ciências voltado às controvérsias suscitadas pelas QSCs possui um potencial considerável para a inovação educativa, que também exige planejamento do ensino e ações bem sustentadas, assim como a participação ativa do professor.

A abordagem de QSCs focada na tomada de decisão no ensino de ciências não deve considerar apenas as estratégias didáticas que favorecem o desenvolvimento de habilidades dos estudantes para realizar suas próprias es- colhas, mas também deve levar em consideração a cultura dos estudantes, que influencia na forma como eles tomam suas próprias decisões. Salientamos a necessidade de relacionar a cultura dos estudantes com a cultura das disciplinas científicas do currículo, pois, desse modo, os estudantes terão melhores condições e oportunidades para aprender a fundamentar suas escolhas a partir de sua própria realidade.

A abordagem de QSCs em sala de aula pode favorecer o desenvolvimento de habilidades de pensamento crítico nos estudantes, tais como a habilidade para resolver problemas e tomar decisões. No entanto, o desenvolvimento de habilidades de ordem superior depende do nível educativo no qual foi desenvolvido o trabalho com QSCs, assim como do tipo de estratégias utilizadas pelo professor para o favorecimento de determinadas habilidades.

Finalmente, salientamos que as análises realizadas permitiram-nos estabelecer as dificuldades curriculares, pedagógicas e formativas enfrentadas pelos professores de ciências em serviço sobre a abordagem de QSCs em suas práticas docentes.

As dificuldades curriculares que foram caracterizadas estiveram relacionadas com a influência do currículo tradicional de ciências, que restringe a prática dos professores em termos da definição de seu próprio trabalho didático. Outras dificuldades semelhantes de tipo curricular foram caracterizadas na pesquisa realizada por Reis e Galvão (2008), em que os autores salientaram o medo dos professores para enfrentar conflitos com os diretores de escolas, que controlam as discussões sobre o currículo, e os constrangimentos impostos pelo excesso de conteúdos ou por sistemas de avaliação que não valorizam as QSCs.

Santos e Mortimer (2009) também apontaram dificuldades curriculares da abordagem de QSCs no ensino de ciências associadas à carga horária das disciplinas de ciências (química) e à dificuldade para construir equipes integrais de professores. No entanto, os autores citados salientam que os resultados obtidos por eles em 
sua pesquisa evidenciam a inserção de aspectos sociocientíficos nos currículos de ciências como um aspecto importante para a formação cidadã.

As dificuldades pedagógicas estiveram relacionadas com a existência, em alguns casos, do ensino de ciências tradicional centrado em conteúdos disciplinares. Reis e Galvão (2008) também destacaram dificuldades pedagógicas atreladas à abordagem de QSCs, na medida em que os professores participantes de sua pesquisa evidenciaram falta de conhecimentos sobre aspectos políticos, sociológicos e éticos das QSCs.

As dificuldades formativas estiveram relacionadas principalmente com a preparação pedagógica por parte de alguns professores, que além de não terem realizado cursos de licenciatura, tinham pouca experiência docente. No caso da maior parte de professores que tinha uma preparação específica em educação, as dificuldades estiveram relacionadas com a falta de preparação na pesquisa como elemento relevante da atuação docente.

Finalmente, nesta pesquisa, constituímos evidências empíricas que mostram a potencialidade da abordagem de QSCs para repensar a prática do professor de ciências em termos de orientar de melhor forma tanto a tomada de decisão dos alunos, quanto o desenvolvimento de algumas habilidades de pensamento crítico. 


\section{Referências}

ABD-EL-KHALICK, Fouad. Socioscientific issues in pre-college science classrooms: the primacy of learners' epistemological orientations and views of nature of science. In: ZEIDLER, Dana (Org.). The role of moral reasoning on socioscientific issues and discourse in science education. The Netherlands: Kluwer Academic Publishers, 2003. p. 41-61.

BODNER, George; MACISAAC, Daniel. A critical examination of relevance in science education research. In: The Annual Meeting of the National Association Research in Science Teaching, San Francisco, 1995.

CARR, Wilfred. Una teoría para la educación: hacia una investigación educativa crítica. Tradução de Pablo Manzano. Madrid: Morata, 1996.

CARR, Wilfred; KEMMIS, Stephen. Teoría crítica de la enseñanza: la investigación-acción en la formación del profesorado. Tradução de J. A. Bravo. Barcelona: Martínez Roca, 1988.

CARVALHO, Anna Maria. Uma metodologia de pesquisa para estudar os processos de ensino e aprendizagem em salas de aula. In: SANTOS, Flávia M. Teixeira dos; GRECA, lleana Maria (Orgs.). A pesquisa em ensino de ciências no Brasil e suas metodologias. ljuí: Unijuí, 2006. p. 13-48.

CORTI, Ana Paula; FREITAS, Maria Virgínia de; SPÓSITO, Marília Pontes. 0 encontro das culturas juvenis com a escola. São Paulo: Ação Educativa, 2001.

CORTI, Ana Paula; SOUZA, Raquel. Diálogos com o mundo juvenil: subsídios para educadores. São Paulo: Ação Educativa, 2005.

HALPERN, Diane. Teaching critical thinking for transfer across domains. American Psychologist, v. 53, n. 4, p. 449-455, 1998.

Critical thinking assessment using everyday situations: background and scoring standards $\left(2^{\circ}\right.$ Report). Unpublished manuscript. Claremont, CA: Claremont McKenna College, 2006.

KINCHELOE, Joe; MCLAREN, Peter. Repensando a teoria crítica e a pesquisa qualitativa In: DENZIN, Norman; LINCOLN, Yvonna (Orgs.). 0 planejamento da pesquisa qualitativa: teorias e abordagens. 2. ed. Tradução de Sandra Regina Netz. Porto Alegre: Artes Médicas, 2006. p. 281-312.

KORTLAND, Koos. An STS case study about students' decision making on the waste issue. Science Education, v. 80, n. 6, p. 673-689, 1996.

LEAL, Murilo; ROCHA, Maria Fernanda. Ensino de química, cultura escolar e cultura juvenil: possibilidades e tensões. In: ROSA, Maria Inês Petrucci; ROSSI, Adriana Vitorino (Orgs.). Educação química no Brasil: memórias, políticas e tendências. Campinas: Átomo. 2008. p.183-215.

MARTÍNEZ PÉREZ, Leonardo Fabio. A abordagem de questões sociocientíficas na formação continuada de professores de ciências: contribuições e dificuldades. Tese (Doutorado) - Faculdade de Ciências, Universidade Estadual Paulista, Bauru, 2010.

MOLTO, Cristina Cardona. Introducción a los métodos de investigación en educación. Madrid: EOS, 2002.

PEDRETTI, Erminia. Septic tank crisis: a case study of science, technology and society education in an elementary school. International Journal of Science Education, v. 19, n. 10, p. 1211-1230, 1997.

Teaching science, technology, society and environment (STSE) education: preservice teachers' philosophical and pedagogical landscapes. In: ZEIDLER, Dana (Org). The role of moral reasoning on socioscientific issues and discourse in science education. The Netherlands: Kluwer Academic Publishers, 2003. p. 219-239.

PEDRETTI, Erminia et al. Promoting issues-based STSE: perspectives in science teacher education: problems of identity and ideology. Science \& Education, v. 17, n. 8-9, p. 941-960, 2008.

RAMSEY, John. The science education reform movement: implications for social responsibility. Science Education, v. 77, n. 2, p. 235-258, 1993. 
RATCLIFFE, Mary. Pupil decision-making about socio-scientific issues within the science curriculum. International Journal of Science Education, v. 19, n. 2, p.167-182, 1997.

RATCLIFFE Mary; GRACE Marcus. Science education for citizenship: teaching socio-scientific issues. Maidenhead: Open University Press, 2003.

REIS, Pedro; GALVÃO, Cecília. Os professores de ciências naturais e a discussão de controvérsias sociocientifícas: dois casos distintos. Revista Electrónica de Enseñanza de la Ciencias, v. 7, n. 3, p. 746-772, 2008.

SANTOMÉ, Jurjo Torres. As culturas negadas e silenciadas no currículo. In: SILVA, Tomaz Tadeu da (Org.). Alienígenas na sala de aula: uma introdução aos estudos culturais em educação. 3. ed. Tradução de Tomaz Tadeu da Silva. Petrópolis: Vozes, 2001. p. 159-177.

SANTOS, Wildson. Aspectos sócio-científicos em aulas de química. Tese (Doutorado) - Faculdade de Educação, Universidade Federal de Minas Gerais, Belo Horizonte, 2002.

SANTOS, Wildson; MORTIMER, Eduardo Fleury. Tomada de decisão para ação social responsável no ensino de ciências. Ciência \& Educação, v. 7, n. 1, p. 95-111, 2001.

. Abordagem de aspectos sociocientíficos em aulas de ciências: possibilidades e limitações. Investigações em Ensino de Ciências, v. 14, n. 2, p. 191-218, 2009.

WATTS, Mike et al. Event-centred-learning: an approach to teaching science technology and societal issues in two countries. International Journal of Science Education, v. 19, n. 3, p. 341-351, 1997.

Recebido em: 12.04.2011

Aprovado em: 13.03.2012

Leonardo Fabio Martínez Pérez é doutor em Educação para a Ciência pela Universidade Estadual Paulista "Júlio de Mesquita Filho" (UNESP), licenciado em Química e mestre em Docência da Química pela Universidad Pedagogica Nacional (Bogotá, Colômbia) na qual atua como Professor do Departamento de Química e orienta trabalhos de pesquisa na linha de CTSA no Ensino de Ciências.

Washington Luiz Pacheco de Carvalho é doutor em Educação pela Universidade Estadual de Campinas (UNICAMP), licenciado em Física pela Universidade Estadual de Londrina e mestre em Ensino de Ciências pela Universidade de São Paulo. Realizou estágio de Pós-Doutoramento na Michigan State University e, atualmente, é professor da Faculdade de Engenharia de Ilha Solteira/UNESP. E-mail: washcar@dfq.feis.unesp.br. 